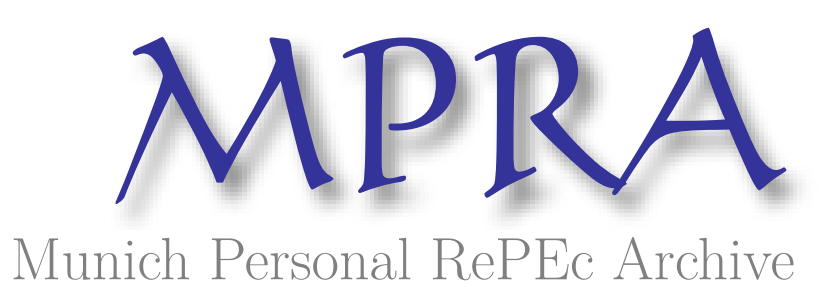

\title{
Banking Resolution: Expansion of the Resolution Toolkit and the Changing Role of Deposit Insurers
}

\author{
Defina, Ryan \\ International Association of Deposit Insurers
}

20 August 2021

Online at https://mpra.ub.uni-muenchen.de/110801/

MPRA Paper No. 110801, posted 24 Nov 2021 04:23 UTC 


\section{Banking Resolution: Expansion of the Resolution TOOLKIT AND the CHANGING ROLE OF DEPOSIT INSURERS}

\section{Executive summary}

In this Policy Brief, we provide quantitative evidence demonstrating that the resolution toolkit has expanded considerably since the 2008 Global Financial Crisis (GFC). Purchase and assumption transactions, bridge bank facilitation and bail-in mechanisms have all become more available for bank resolution purposes. The use of such resolution tools is increasingly subject to least cost rules and to systemic failure considerations. These resolution tools may be available to different authorities, such as deposit insurers or resolution authorities, depending on the jurisdiction in question. Two of the three statistical models applied point to a significant increase in resolution powers for deposit insurers.

\section{Introduction and purpose}

Deposit insurance systems have undergone a period of substantial growth over the last century. There are now approximately 140 systems in total, representing jurisdictions totalling $75 \%$ of global gross domestic product. Data collections from the World Bank, combined with IADI data demonstrate that most deposit insurance systems were introduced gradually from the 1960 s onwards. ${ }^{1}$ Roughly half of all deposit insurance systems emerged post the year 2000 , with particularly rapid growth post the 2008 GFC.

Deposit insurers (DI) do not tend to follow a standard model in their development. ${ }^{2}$ Some will commence as simple pay boxes and gradually build the case for greater powers and/or an expanded toolkit. Others will benefit from a period of positive sentiment (and associated momentum) that yields regulatory reform(s) and development of a more comprehensive system, with considerable powers and tools, from scratch. Contemporary examples of the latter are that of the new systems in New Zealand and South Africa whereby design is being informed by feedback from the IADI Core Principles and guidance from the FSB, IMF and World Bank. At the time of writing, only $25 \%$ of deposit insurers function as a simple paybox. ${ }^{3}$ In 2011 , this share was still at $38 \%$.

This paper seeks to explore changing powers of deposit insurers (DI) in resolution activities, changes in the resolution toolkit, and changes in the conditions governing the use of these resolution tools. It wishes to determine whether any observed changes are statistically significant or simply a result of random variation over time. Potential reasons for these changes include, but are not limited to:

- Emergence of new tools and/or a general increase in the palatability of certain tools e.g. bail-in since the GFC

- Identification of gaps in existing resolution regimes e.g. limitations in resolution of "too big to fail" banks

- Resolution standards ${ }^{4}$ such as the FSB Key Attributes, IADI Core Principles and EU BRRD have provided an avenue for consensus and formalisation of standards regarding the availability and use of resolution tools

\footnotetext{
${ }^{1}$ Early exceptions include the United States of America and Germany (partially) which were operational in the 1930 s.

${ }^{2}$ Defina (2021) found that DI mandates are typically broader in more mature systems. In addition, those systems established post the 2008/09 Global Financial Crisis have also been identified as holding broader mandates than others, on average. However, it should be noted that numerous caveats and exceptions are apparent in the data. Other key design factors for a deposit insurer such as the degree of legal independence, coverage levels, and funding were not found to correlate with DI maturity.

${ }^{3}$ Deposit insurers that are members of IADI tend to have broader mandates on average. The 2020 IADI Annual Survey identified $79 \%$ of IADI members had a mandate broader than a paybox, while this figure was $64 \%$ for non-members.

${ }^{4}$ Henceforth the FSB Key Attributes, IADI Core Principles and EU BRRD will denote the Financial Stability Board Key Attributes of Effective Resolution Regimes for Financial Institutions, International Association of Deposit Insurers Core Principles for Effective Deposit Insurance Systems and European Union Bank Recovery and Resolution Directive respectively.
} 
- Redistribution of tools between central banks, supervisors, resolution authorities and deposit insurers

- Political changes dictating the relative appetite for adjusting DI system configuration

Earlier work by Baudino et al (2019) explored the use of DI funds in bank failure management. This included widespread utilisation of non-payout related activities, particularly capital and liquidity support measures, and purchase and assumption (P\&A) transactions. While presenting an informative and detailed snapshot of current DI resolution practices, the Baudino et al (2019) paper is broadly cross-sectional (exploring a single point in time) and does not consider changes over time. As such, this paper seeks to build on the Baudino et al (2019) findings, offering additional historical context and perspective to the topic.

\section{Global standards}

The resolution toolkit of a deposit insurer does not exist in a vacuum. There are a multitude of global standards that have been developed, endorsed and adopted, mostly in response to experiences of the GFC. A broad-based shift in a number of design features, and changes in resolution tools available, has been observed within the field of deposit insurance post-crisis. This is aligned with overall reform in bank supervision and resolution activities that has been reinforced by the strengthening of international standards for deposit insurers.

The FSB Key Attributes (2014) seek to reduce the exposure of taxpayers to losses through the provision of solvency support (essentially advising against publically-funded bail outs). The Key Attributes are comprehensive in the sense that they touch on a broad suite of relevant considerations including financing, safeguards, cross-border cooperation, crisis management, resolution planning, and information sharing. The FSB Thematic Review on Deposit Insurance (FSB 2012) offers detail on deposit insurance reforms undertaken in response to the GFC, along with a number of informative case studies. It is important to recognise that the Key Attributes were primarily designed to offer a framework for the resolution of global systemically important banks (G-SIBs).

The IADI Core Principles (2008, revised 2014) are reflective of, and designed to be adaptable to, a broad range of jurisdictional circumstances, settings and structures. They are intended as a framework supporting effective deposit insurance practices. Within the context of this paper, two Core Principles (CP) are of particular relevance. CP9 offers clear guidance on the funding framework for DI operations and resolution activities. While CP14, in particular Essential Criteria 4, recognises that many deposit insurers have resolution roles that are not limited to depositor reimbursement.

On a European level, the BRRD (2014) has provided comprehensive and effective arrangements for EU member states and for the Single Resolution Board (SRB) to deal with failing banks. This has in-effect standardised the resolution toolset available in the EU. The directive also includes a least cost principle and formalised the bail-in mechanism to promote loss sharing between bank shareholders, bank creditors and the deposit insurer.

\section{Definitions and key terms}

In order to frame the analysis accurately, a number of concepts need to be clarified. These are mostly extracted directly from the IADI Glossary.

Bail-in within Resolution. A mechanism to recapitalise a bank in resolution or effectively capitalise a bridge bank, under specified conditions, through the write-down, conversion or exchange of debt instruments and other senior or subordinated unsecured liabilities of the bank in resolution into/for, equity or other instruments in that bank, the parent company of that bank or a newly formed bridge bank, as appropriate to legal frameworks and market capacity.

Bridge Bank. An entity that is established to temporarily take over and maintain certain assets, liabilities and operations of a failed bank as part of the resolution process.

Deposit Reimbursement. A resolution method that involves the reimbursement of deposits to insured depositors. 
Lender of Last Resort. ${ }^{5}$ Banks typically turn to their lender of last resort when they cannot get the funding they need for their daily business. This can happen in periods of financial turmoil, when banks may have doubts about lending to each other and lots of people may suddenly want to withdraw their money from their bank account. In situations like that, central banks act as the lender of last resort. Central banks have traditionally held this role because they are primarily the ones responsible for ensuring that financial markets function smoothly and the financial system is stable.

Liquidation. The winding-down (or winding-up, as used in some jurisdictions) of the business affairs and operations of a failed bank through the orderly disposition of its assets after its licence has been revoked and it has been placed in receivership. In most jurisdictions, it is synonymous with "receivership".

Open Bank Assistance. Action taken by the designated authority, in which a bank in danger of failing receives assistance in the form of a direct loan, an assisted merger, a purchase of assets, or other means to prevent its failure.

Purchase and Assumption Transaction. A resolution method in which a healthy bank or a group of investors assume some or all of the obligations, and purchase some or all of the assets of the failed bank.

Resolution Authority. A public authority that, either alone or together with other authorities, is responsible for the resolution of financial institutions established in its jurisdiction (including resolution planning functions).

Systemic Failure Criteria. Specific procedures and/or policy that apply only during the period immediately preceding, and throughout, the resolution of a systemic bank.

\section{Methodology and results}

\subsection{The data}

The IADI Annual Survey has been conducted throughout the period 2012-2020 (inclusive). ${ }^{6}$ As such, the dataset now offers unique insights into the evolution of measures over successive survey iterations. This will serve as the main quantitative source throughout the paper. ${ }^{7}$ There are however some constraints. In particular, not every data item of interest is collected every year. Time series are constructed with a focus on temporal coherence to ensure they are fit for the purposes of this analysis.

Time series were constructed for a number of Annual Survey questions relating to resolution activities. These include:

Q10. DIA's Additional Key Powers [Answer options: Lender of Last Resort; Resolution Authority; Banking Supervision]

Q56. What resolution tools or methods are available for bank resolution? [Answer options: Purchase and Assumption; Open Bank Assistance; Bridge Bank; Liquidation; Deposit Reimbursement]

Q57. Is the least-cost rule used to determine the method of failure resolution?

Q58. In the case of a systemic failure, are there different criteria used in determining which resolution procedures to adopt?

Conceptually, it should be noted that deposit insurers are invited to answer these survey questions while considering the broader financial safety net within their jurisdiction. This means that not all the resolution tools highlighted in this paper are explicitly available to the deposit insurer directly, but are available within the jurisdiction in which the given deposit insurer operates. The institution tasked with implementing any specific resolution tool may be the resolution authority, supervisor and/or the central bank (often in a coordinated manner with the deposit insurer). For this reason,

\footnotetext{
${ }^{5}$ Source: European Central Bank (2019)

${ }^{6} \mathrm{~A}$ small number of surveys were conducted by IADI prior to 2012, but due to subsequent changes in questionnaire design, do not provide comparable data points to extend the time series.

${ }^{7}$ The Annual Survey sample size has in recent years exceeded well over one hundred participants (peaking at 135 in 2018 ), and consistently represents over $85 \%$ of deposit insurers globally.
}

IADI Policy Brief No 3 
questions on resolution tools are treated separately from those relating directly to key powers of the deposit insurer. Within the suite of resolution tools, we distinguish between the availability and the conditions governing their use.

Other limitations are apparent which constrain the analysis somewhat. The question of additional key powers only exists from 2014 onwards, and hence the time series consists of seven points rather than nine. Regarding resolution tools, bail-in is only made available as an answer option from 2016, limiting this series to five points rather than nine.

\subsection{Observations}

Data are compiled from as many successive survey iterations as possible for each data item, averaged over all available respondents, and presented in the charts below.

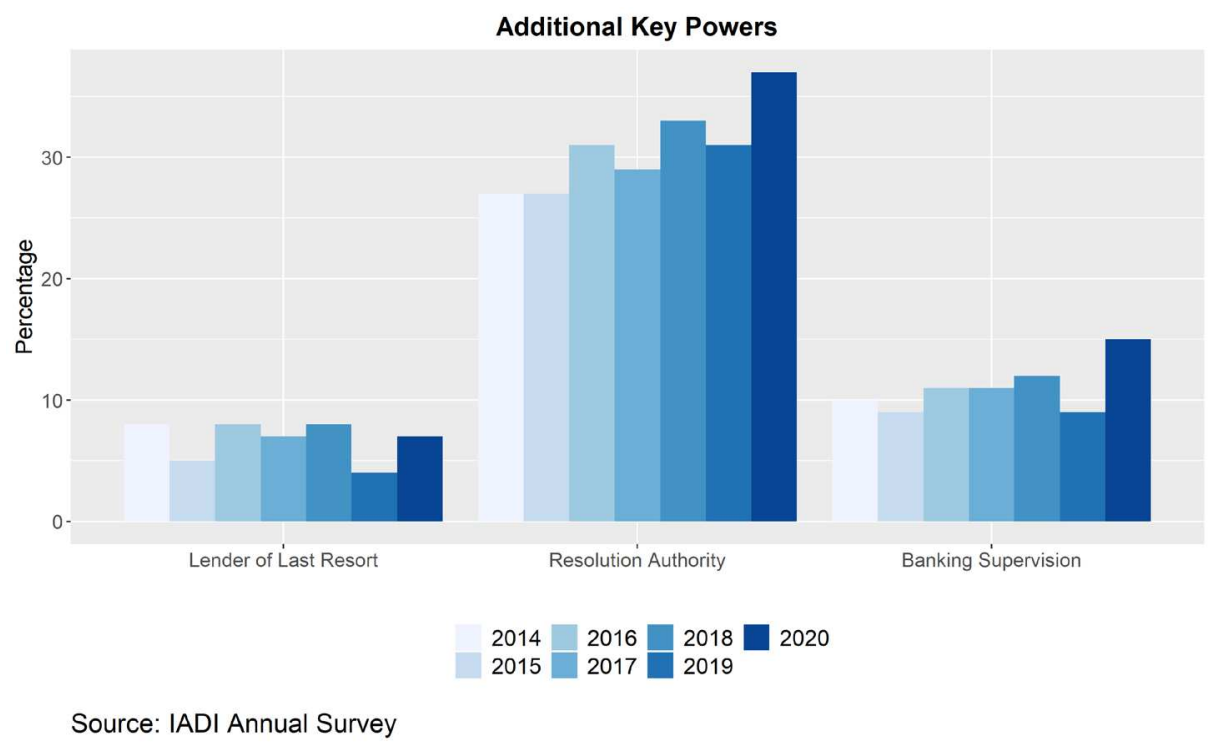

The chart above suggests that the prevalence of a DI acting as a lender of last resort and/or banking supervision power has not changed a great deal over the nine years. ${ }^{8} \mathrm{It}$ is asserted that the (small) observed changes are due to changes in the sample composition over time. However, the resolution authority role does present some evidence of being more prevalent among deposit insurers - up ten percentage points to 37\% compared to 2014 .

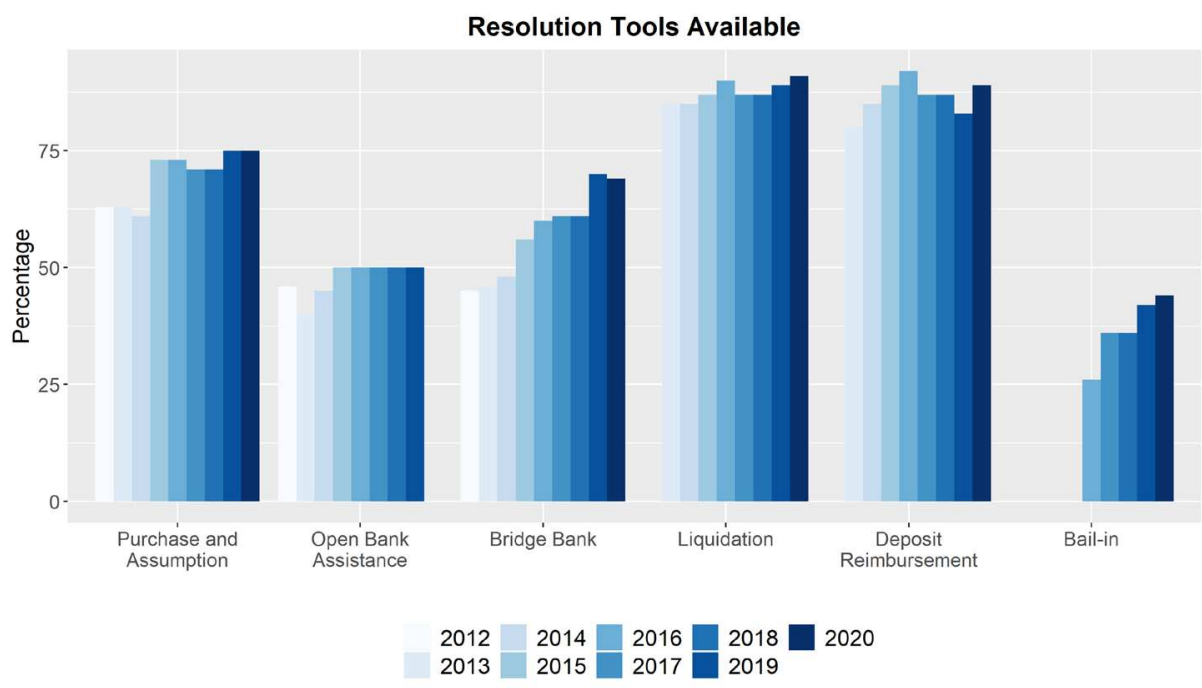

Source: IADI Annual Survey

\footnotetext{
${ }^{8}$ For banking supervision we observe a substantial uptick in 2020. It is unclear as to whether this increase in prevalence will be sustained in the future. Subsequent iterations of the IADI Annual Survey will assist in making this determination.
} 
Open bank assistance, liquidation and deposit reimbursement have all remained relatively stable over the nine year window of survey data. Conversely, purchase and assumption, the use of bridge banks and bail-in facilities have all risen to different extents. In 2020, P\&A transactions were identified as an available resolution tool in $75 \%$ of deposit insurers surveyed, relative to $60 \%$ eight years prior. The ability to conduct a resolution using a bridge bank has sharply risen from $45 \%$ to $70 \%$ in the jurisdictions surveyed. Finally, bail-in facilities have increased in prevalence from $25 \%$ to $40 \%$, in line with their promotion under the FSB Key Attributes, albeit observed with the caveat of a rather short time series. Overall, the figures indicate that the resolution toolkit has changed markedly. While liquidation and payout is still utilised, additional mechanisms have clearly been added, offered mostly as policy options for deposit insurers and resolution authorities to consider when resolving a failed institution.

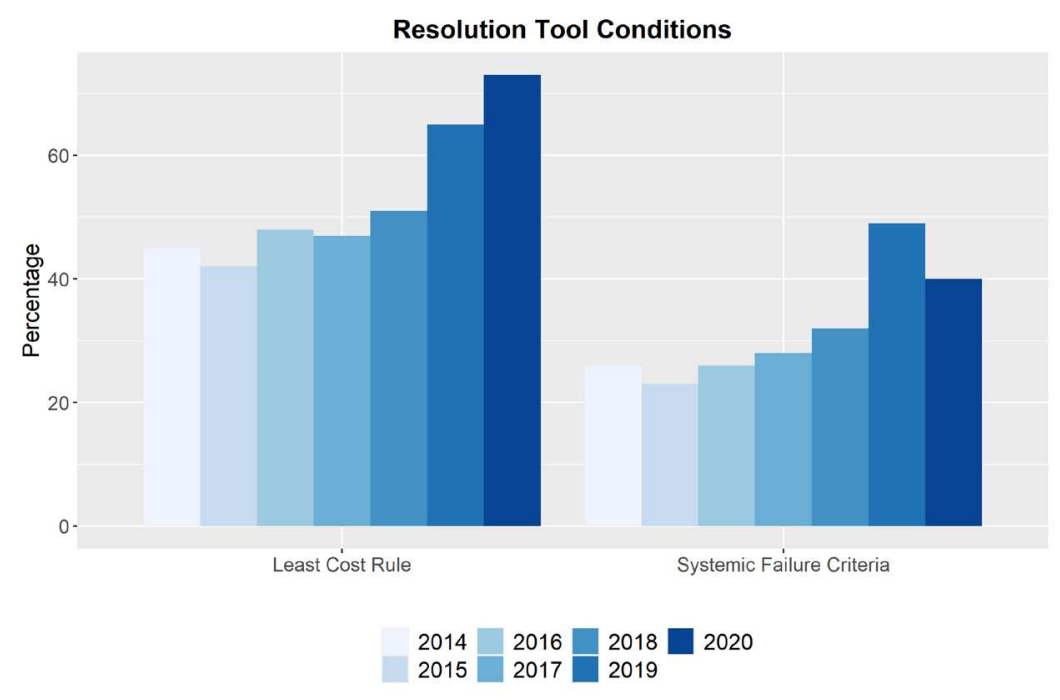

Source: IADI Annual Survey

Baudino et al (2019) indicate that a number of policy conditions frame choices surrounding the use of DI resources. ${ }^{9}$ Two such conditions include least cost rules/tests and systemic failure criteria. Both can shape the very fundamentals of DI involvement in bank resolution activities, and present ongoing challenges in implementation. The prevalence of these considerations has increased, which is not surprising given that they operate within a context of a broader resolution toolkit. Without these conditions (and undoubtedly many others not mentioned), the deposit insurer and/or resolution authority has few principles with which to formally assess which tool to utilise during bank failure resolution. ${ }^{10}$

\subsection{Comparing matched samples}

The IADI Annual Survey is a voluntary data collection exercise. Each year the sample will therefore change due to a number of factors: individual response propensity, existence of the $\mathrm{DI}$, inclusion on the sample frame ${ }^{11}$, and a multitude of other reasons. Changes in sample composition over time can introduce additional uncertainty regarding the interpretation of changes in the survey estimates over time. One approach to address this issue is via decomposition of movements ${ }^{12}$ into two sources: changes in prevalence in the common sample between two successive survey iterations and; changes in prevalence for sample only measured in one of two successive survey iterations.

\footnotetext{
${ }^{9}$ Croitoru et al (2018) also flags a number of design features that may seek to mitigate moral hazard considerations.

${ }^{10}$ This does not imply that the selection of a resolution tool cannot be made effectively without these conditions formally in place. In some instances the conditions are considered relatively directly, however they may not be formalised in legislation. Other jurisdictions might seek to incorporate additional factors specific to their institution that are not disclosed to the IADI Secretariat. ${ }^{11}$ The sample frame is a list of potential survey respondents, with which some or all are invited to participate in a data collection. For the IADI Annual Survey, all known deposit insurers are approached with the exception of those operating within jurisdictions under sanctions (as defined by the Bank for International Settlements).

${ }^{12}$ See Preston (2005) for further methodological details and natural extensions.
} 
A number of large annual movements are observed in the 2019 figures. To investigate the extent of a potential rotation effect, tables in the appendix present the change in prevalence in common sample, compared to the change in prevalence for all sample, and derive the rotation effect. This is only conducted for 2019. Earlier years are omitted as movements are substantially smaller and evidence of a potential rotation effect is comparatively low.

The matched analysis demonstrates some evidence of a sample rotation effect for a selection of data items. It sets the cut-off at three percentage points to denote sufficient evidence of an effect. ${ }^{13}$ One may conclude that the movements observed in 2019 for data items exhibiting evidence of a rotation effect should be interpreted with a degree of caution. It is possible that the extent of such movements may have been driven by changes in the sample, and that mean reversion in subsequent survey iterations is likely.

\section{TABLE ONE: SAMPLE ROTATION EFFECTS}

Some evidence of rotation effect

Bridge Bank; Bail-in; Banking Supervision;

Least Cost Rule; Systemic Failure Criteria
No clear evidence of rotation effect

Purchase and Assumption; Open Bank Assistance; Liquidation; Deposit Reimbursement; Lender of Last Resort; Resolution Authority

\subsection{Testing for a time effect}

The core research question in this paper effectively boils down to whether growth in the data items aforementioned is present, and to what extent such growth is significant, acting as a proxy for corresponding reform in the deposit insurance field. This section explores numerous approaches to test for and quantify a potential time effect. Formally, the paper explores the following umbrella of reasoning and associated null / alternative hypothesis.

$$
\begin{aligned}
& H_{0}: \hat{\beta}_{1}=0 \text { i.e. there is no time effect in the population of the given data item } \\
& H_{A}: \hat{\beta}_{1} \neq 0 \text { i.e. there is a time effect in the population of the given data item }
\end{aligned}
$$

Model A: Time-trend effect in aggregate time series. A simple method to test for growth over time is to regress the time series of each respective data item by a linear time variable. This can be modelled through the following specification, whereby $Y_{t}$ denotes the variable of interest ${ }^{14}$, averaged at time t. $\epsilon_{t}$ is the residual i.e. that which is not explained by the linear time variable.

$$
Y_{t}=\hat{\beta}_{0}+\hat{\beta}_{1} \mathrm{t}+\epsilon_{t}
$$

An alternative approach is to fit models at the individual response level, rather than use the aggregate time series. To do so we note the key structure in the data. All response variables (resolution tools) are binary and measure whether a given resolution tool was available to a deposit insurer at a given point in time. As such, we construct a model using a logistic regression approach with an underlying Bernoulli response ${ }^{15}$ distribution to model $Y_{i t}$.

$$
Y_{i t} \sim \operatorname{Bernoulli}\left(p_{i t}\right) \quad Y_{i t}=\left\{\begin{array}{ccc}
1 ; & \text { if DI i has resolution tool } \mathrm{y} \text { at time } \mathrm{t} \\
0 ; & \text { otherwise }
\end{array}\right.
$$$$
\text { which implies } \operatorname{Pr}\left(Y_{i t}=1\right)=\mathrm{E}\left(Y_{i t}\right)=p_{i t}
$$

Model B: Independent unit-level model. This model fits a logistic regression to the full unit-level panel dataset. It assumes independence between all observations over time, which while not realistic, dramatically simplifies the model and its subsequent interpretation. The model is defined as a linear model of the log odds of resolution tool y being available to $\mathrm{DI} i$ at time $\mathrm{t}$.

\footnotetext{
${ }^{13}$ This threshold was determined based on practical significance and does not constitute a formal statistical hypothesis test.

${ }^{14}$ For this case, the variable of interest was the prevalence of a given resolution tool, as represented by an aggregate time series.

${ }^{15} \mathrm{~A}$ probit response distribution would be equally appropriate in this instance. The logit response is viewed as somewhat easier to interpret as it is effectively fitting a linear model to the log odds of an outcome, rather than a (difficult to translate) inverse normal distribution.
} 


$$
\log \left(\frac{p_{i t}}{1-p_{i t}}\right)=\hat{\beta}_{0}+\hat{\beta}_{1} \mathrm{t}
$$

Model C: Correlated unit-level model. An extension of the independent model is one that incorporates a correlation structure between data points from the same DI over time. The technical definition is commonly referred to as the 'random effects' model. ${ }^{16}$ An additional parameter $\gamma_{i}$ corresponds to DI-level random intercepts, which remain consistent over time for each given DI. ${ }^{17}$

$$
\log \left(\frac{p_{i t}}{1-p_{i t}}\right)=\hat{\beta}_{0}+\hat{\gamma}_{i}+\hat{\beta}_{1} \mathrm{t}
$$

A summary of results for all three models is in the table below. Ticks $(\checkmark)$ represent sufficient evidence to reject the null hypothesis that there is no time effect, and therefore implies a gradual increase in resolution tool availability. Crosses $(\mathbf{X})$ represent insufficient evidence to reject the null hypothesis, and thus a reduced argument for growth in resolution tool availability. More detailed figures are available in the Appendix.

\begin{tabular}{|c|c|c|c|}
\hline Data Item & Model A & Model B & Model C \\
\hline \multicolumn{4}{|c|}{ Changes in Deposit Insurers' Key Powers } \\
\hline Lender of Last Resort & $x$ & $x$ & $x$ \\
\hline Resolution Authority & $\sqrt{ }$ & $x$ & $\sqrt{ }$ \\
\hline Banking Supervision & $x$ & $x$ & $\checkmark$ \\
\hline \multicolumn{4}{|c|}{ Changes in the Resolution Toolkit } \\
\hline Purchase and Assumption & $\checkmark$ & $\checkmark$ & $\checkmark$ \\
\hline Open Bank Assistance & $\checkmark$ & $\mathrm{x}$ & $\checkmark$ \\
\hline Bridge Bank & $\sqrt{ }$ & $\checkmark$ & $\checkmark$ \\
\hline Liquidation & $x$ & $x$ & $x$ \\
\hline Deposit Reimbursement & $x$ & $x$ & $x$ \\
\hline Bail-in & $\checkmark$ & $\checkmark$ & $\checkmark$ \\
\hline \multicolumn{4}{|c|}{ Changes in conditions governing the Resolution Toolkit } \\
\hline Least Cost Rule & $\checkmark$ & $\checkmark$ & $\checkmark$ \\
\hline Systemic Failure Criteria & $\checkmark$ & $\sqrt{ }$ & $\checkmark$ \\
\hline
\end{tabular}

\section{TABLE TWO: STATISTICALLY SIGNIFICANT CHANGES OVER TIME}

\footnotetext{
${ }^{16}$ Hsiao (2003) offers a comprehensive review of these methods and discusses suitable applications.

${ }^{17}$ The random effects parameter was found to be statistically significant for all data items analysed in this paper.
} 


\section{Future directions}

This paper intentionally applies relatively simple methods and utilises historical survey data sources only. ${ }^{18}$ The decision to do so is in part motivated by pragmatism, the wish to simplify the interpretation of results, but equally importantly to highlight the value proposition of existing IADI data. Future work on the subject matter of resolution toolkit evolution could involve exploration of a number of additional dynamics:

Tool effectiveness and financial system implications. This paper focuses on whether particular tools are available, rather than analysing how they are used, or their relative effectiveness (and limitations) when applied in practice. Future work may seek to flesh out these useful details and draw conclusions as to the broader implications of an expanding DI resolution toolkit on financial system stability.

Identifying challenges for practitioners. The availability of additional tools presents numerous challenges for the deposit insurer. These range from recruiting suitable technical expertise, to acquiring appropriate IT infrastructure, to legislative considerations, and many others. Such challenges underscore the relevance of results presented in this paper for deposit insurance practitioners, and likely warrant further exploration in the future.

Additional survey(s). Further information over time will of course provide a more robust analysis. In addition, targeted case studies could be analysed to determine specific factors that may be driving overall trends in the dataset e.g. challenges of tool application, and ascertaining the necessary preconditions for role expansion. The mostly crosssectional analysis in this paper will potentially smooth over many of these underlying driving forces.

Unpacking causality. As a general proposition, continuing to explore the instances where observed correlation can be attributed to causation can greatly assist in informing policy discussions. Methodologies for isolating causality are widely available. ${ }^{19}$

Collate further historical data. Current time series data available do not capture the GFC or the period leading up to it. The beginning of this paper alludes to a number of previous data collection initiatives in the field of deposit insurance. Additional efforts to integrate collections from the IMF and World Bank in the early 2000s may yield informative insights for policymakers. This would offer an opportunity to conduct a more comprehensive intervention analysis, and thus better understand the evolution of bank resolution before, during, and after the GFC policy responses.

Forecasting. Well-established time series methods ${ }^{20}$ are available to project future scenarios regarding the deposit insurer's resolution toolkit. Such figures may provide an avenue to infer about emerging opportunities and challenges for deposit insurers and resolution authorities, along with highlighting the evolution of the role played by bank supervisors. However, further data will be needed in order to lend sufficient statistical power to any inference, and to streamline the forecasting bands to a sensible range. ${ }^{21}$

\footnotetext{
${ }^{18}$ At its very core, modelling is an exercise in abstraction and simplification of reality to aid analysis. The modelling approaches used in this paper are purposefully chosen to be parsimonious, and hence by definition, limitations are realised on a semi-regular basis. Such abstractions include omission of key variables and the imposition of parametric assumptions concerning the nature of underlying concepts or relationships between such concepts e.g. this paper assumes linearity in conditional relationships over time and on the structure of associated variance-covariance matrices (particularly off-diagonal elements). Non-compliance with these (or other unlisted) modelling assumptions increases the likelihood that bias is being introduced in the parameter estimates.

${ }^{19}$ Pearl (2009) offers a comprehensive overview of potential approaches.

${ }^{20}$ Multivariate methods can also incorporate additional factors when generating forecasts. For instance, system mandate (paybox, paybox-plus, loss minimiser, risk minimiser) and geographic region often provide useful explanatory power when comparing deposit insurers among many jurisdictions.

${ }^{21}$ Attempts to forecast using the current dataset yielded rather uninspiring results. Automated model selection methodologies such as Auto-ARIMA return an ARIMA $(0,1,0)$ which implies very little structure to inform forecasting beyond the linear time trend.
} 


\section{References}

Baudino, P., Defina, R., Fernández Real, JM., Hajra, K., Walters, W. (2019). Bank failure management - the role of deposit insurance. Financial Stability Institute Insights No. 17.

Croissant, Y. (2020). pglm: Panel Generalized Linear Models. $R$ package version 0.2-2.

Croitoru, O. Dobler, M., Molin, J. (2018). Resolution Funding: Who Pays When Financial Institutions Fail? International Monetary Fund Technical Guidance Note.

Defina, R. (2021). The Geographic Dynamics of Deposit Insurance. International Association of Deposit Insurers Policy Brief No. 2.

European Central Bank. (2019). What is a lender of last resort? European Central Bank Explainers.

European Union. (2014). Bank Recovery and Resolution Directive 2014/59/EU. Official Journal of the European Union.

Financial Stability Board. (2012). Thematic Review on Deposit Insurance. Financial Stability Board publication.

Financial Stability Board. (2014). Key Attributes of Effective Resolution Regimes for Financial Institutions. Financial Stability Board publication.

Hsiao, C. (2003). Analysis of Panel Data (2nd ed.). New York, NY: Cambridge University Press.

International Association of Deposit Insurers. (2014). IADI Core Principles for Effective Deposit Insurance Systems (revised). International Association of Deposit Insurers publication.

Kane, E., Demirguc-Kunt, A. (2001). Deposit Insurance Around the Globe: Where Does it Work? NBER Working Paper No. 8493.

Pearl, J. (2009). Causal inference in statistics: An overview. Statistics Surveys Vol. 3. No. 96-146.

Preston, J. (2005). Decomposition of Movement Estimates as a Diagnostic Tool for Repeated Business Surveys. Australian Bureau of Statistics Research Paper No. 1352.0.55.073. 


\section{Appendix 22}

\section{Resolution toolset over time}

\section{Prevalence}

\begin{tabular}{|l|l|l|l|l|l|l|}
\hline Year & $\begin{array}{l}\text { Purchase and } \\
\text { Assumption }\end{array}$ & $\begin{array}{l}\text { Open Bank } \\
\text { Assistance }\end{array}$ & Bridge Bank & Liquidation & $\begin{array}{l}\text { Deposit } \\
\text { Reimbursement }\end{array}$ & Bail-in \\
\hline 2012 & $63 \%$ & $46 \%$ & $45 \%$ & not available & not available & not available \\
\hline 2013 & $63 \%$ & $40 \%$ & $46 \%$ & $85 \%$ & $80 \%$ & not available \\
\hline 2014 & $61 \%$ & $45 \%$ & $48 \%$ & $85 \%$ & $85 \%$ & not available \\
\hline 2015 & $73 \%$ & $50 \%$ & $56 \%$ & $87 \%$ & $89 \%$ & not available \\
\hline 2016 & $73 \%$ & $50 \%$ & $60 \%$ & $90 \%$ & $92 \%$ & $26 \%$ \\
\hline 2017 & $71 \%$ & $50 \%$ & $61 \%$ & $87 \%$ & $87 \%$ & $36 \%$ \\
\hline 2018 & $71 \%$ & $50 \%$ & $61 \%$ & $87 \%$ & $87 \%$ & $36 \%$ \\
\hline 2019 & $75 \%$ & $50 \%$ & $70 \%$ & $89 \%$ & $83 \%$ & $42 \%$ \\
\hline 2020 & $75 \%$ & not available & $69 \%$ & $91 \%$ & $89 \%$ & $44 \%$ \\
\hline
\end{tabular}

Change in prevalence and sample rotation effect

\begin{tabular}{|l|l|l|l|l|l|l|l|l|l|}
\hline & \multicolumn{3}{|l|}{ Yurchase and Assumption } & \multicolumn{3}{l|}{ Open Bank Assistance } & \multicolumn{2}{l|}{ Bridge Bank } \\
\hline & $\begin{array}{l}\text { Common } \\
\text { sample }\end{array}$ & $\begin{array}{l}\text { Full } \\
\text { sample }\end{array}$ & $\begin{array}{l}\text { Rotation } \\
\text { effect }\end{array}$ & $\begin{array}{l}\text { Common } \\
\text { sample }\end{array}$ & $\begin{array}{l}\text { Full } \\
\text { sample }\end{array}$ & $\begin{array}{l}\text { Rotation } \\
\text { effect }\end{array}$ & $\begin{array}{l}\text { Common } \\
\text { sample }\end{array}$ & $\begin{array}{l}\text { Full } \\
\text { sample }\end{array}$ & $\begin{array}{l}\text { Rotation } \\
\text { effect }\end{array}$ \\
\hline 2019 & $2 \%$ & $4 \%$ & $2 \%$ & $-1 \%$ & $0 \%$ & $1 \%$ & $5 \%$ & $9 \%$ & $4 \%$ \\
\hline
\end{tabular}

\begin{tabular}{|c|c|c|c|c|c|c|c|c|c|}
\hline \multirow[t]{2}{*}{ Year } & \multicolumn{3}{|c|}{ Liquidation } & \multicolumn{3}{|c|}{ Deposit Reimbursement } & \multicolumn{3}{|l|}{ Bail-in } \\
\hline & $\begin{array}{l}\text { Common } \\
\text { sample }\end{array}$ & $\begin{array}{l}\text { Full } \\
\text { sample }\end{array}$ & $\begin{array}{l}\text { Rotation } \\
\text { effect }\end{array}$ & $\begin{array}{l}\text { Common } \\
\text { sample }\end{array}$ & $\begin{array}{l}\text { Full } \\
\text { sample }\end{array}$ & $\begin{array}{l}\text { Rotation } \\
\text { effect }\end{array}$ & $\begin{array}{l}\text { Common } \\
\text { sample }\end{array}$ & $\begin{array}{l}\text { Full } \\
\text { sample }\end{array}$ & $\begin{array}{l}\text { Rotation } \\
\text { effect }\end{array}$ \\
\hline 2019 & $-1 \%$ & $2 \%$ & $3 \%$ & $-4 \%$ & $-4 \%$ & $0 \%$ & $0 \%$ & $5 \%$ & $5 \%$ \\
\hline
\end{tabular}

\footnotetext{
22 Throughout the Appendix: *,**,*** denote statistical significance of model coefficients at $5 \%, 1 \%$ and $0.1 \%$ level respectively

${ }^{23}$ No longer collected in the IADI Annual Survey
} 
Testing for a linear trend in time series

\begin{tabular}{|c|c|c|c|c|}
\hline Model & Term & $\begin{array}{ll}\text { Purchase } & \text { and } \\
\text { Assumption } & \end{array}$ & Open Bank Assistance & Bridge Bank \\
\hline$A$ & Intercept & $0.62 * * *$ & $0.44 * * *$ & $0.44 * * *$ \\
\hline$A$ & Time & $0.02 * *$ & $0.01 *$ & $0.03 * * *$ \\
\hline$B$ & Intercept & $0.52 * * *$ & $-0.28 *$ & -0.17 \\
\hline$B$ & Time & $0.11 * *$ & 0.07 & $0.18 * * *$ \\
\hline $\mathrm{C}$ & Intercept & $0.76 * *$ & -0.26 & $-0.74 * *$ \\
\hline $\mathrm{C}$ & Time & $0.22 * * *$ & $0.20 * * *$ & $0.47 * * *$ \\
\hline
\end{tabular}

\begin{tabular}{|l|l|l|l|l|}
\hline Model & Term & Liquidation & $\begin{array}{l}\text { Deposit } \\
\text { Reimbursement }\end{array}$ & Bail-in \\
\hline A & Intercept & $0.85^{* * *}$ & $0.84^{* * *}$ & 0.12 \\
\hline A & Time & 0.00 & 0.00 & $0.04^{*}$ \\
\hline B & Intercept & $1.73^{* * *}$ & $1.70 * * *$ & $-1.70^{* * *}$ \\
\hline B & Time & 0.09 & 0.06 & $0.25^{* *}$ \\
\hline C & Intercept & $2.08^{* * *}$ & $1.92^{* * *}$ & $-3.32^{* * *}$ \\
\hline C & Time & 0.08 & 0.08 & $0.56^{* * *}$ \\
\hline
\end{tabular}

\section{Functions of the deposit insurer over time}

\section{Prevalence}

\begin{tabular}{|l|l|l|l|}
\hline Year & Lender of Last Resort & Resolution Authority & Banking Supervision \\
\hline 2014 & $8 \%$ & $27 \%$ & $10 \%$ \\
\hline 2015 & $5 \%$ & $27 \%$ & $9 \%$ \\
\hline 2016 & $8 \%$ & $31 \%$ & $11 \%$ \\
\hline 2017 & $7 \%$ & $29 \%$ & $11 \%$ \\
\hline 2018 & $8 \%$ & $33 \%$ & $12 \%$ \\
\hline 2019 & $4 \%$ & $31 \%$ & $9 \%$ \\
\hline 2020 & $7 \%$ & $37 \%$ & $15 \%$ \\
\hline
\end{tabular}


Change in prevalence and sample rotation effect ${ }^{24}$

\begin{tabular}{|l|l|l|l|l|l|l|l|l|l|}
\hline & \multicolumn{3}{|l|}{ Lender of Last Resort } & \multicolumn{2}{l|}{ Resolution Authority } & \multicolumn{2}{l|}{ Banking Supervision } \\
\hline & $\begin{array}{l}\text { Common } \\
\text { sample }\end{array}$ & $\begin{array}{l}\text { Full } \\
\text { sample }\end{array}$ & $\begin{array}{l}\text { Rotation } \\
\text { effect }\end{array}$ & $\begin{array}{l}\text { Common } \\
\text { sample }\end{array}$ & $\begin{array}{l}\text { Full } \\
\text { sample }\end{array}$ & $\begin{array}{l}\text { Rotation } \\
\text { effect }\end{array}$ & $\begin{array}{l}\text { Common } \\
\text { sample }\end{array}$ & $\begin{array}{l}\text { Full } \\
\text { sample }\end{array}$ & $\begin{array}{l}\text { Rotation } \\
\text { effect }\end{array}$ \\
\hline 2019 & $-1 \%$ & $-4 \%$ & $3 \%$ & $-2 \%$ & $-2 \%$ & $0 \%$ & $1 \%$ & $-3 \%$ & $4 \%$ \\
\hline
\end{tabular}

\section{Testing for a linear trend in time series}

\begin{tabular}{|l|l|l|l|l|}
\hline Model & Term & Lender of Last Resort & Resolution Authority & $\begin{array}{l}\text { Banking } \\
\text { Supervision }\end{array}$ \\
\hline A & Intercept & $0.07^{* *}$ & $0.24^{* * *}$ & $0.08^{* *}$ \\
\hline A & Time & 0.00 & $0.01^{*}$ & 0.00 \\
\hline B & Intercept & $-2.59^{* * *}$ & $-1.02^{* * *}$ & $-2.30^{* * *}$ \\
\hline B & Time & -0.01 & 0.07 & 0.07 \\
\hline C & Intercept & $-5.53^{* * *}$ & $-2.23^{* * *}$ & $-5.01^{* * *}$ \\
\hline C & Time & 0.13 & $0.17^{* * *}$ & $0.20^{* *}$ \\
\hline
\end{tabular}

\section{Resolution tool conditions}

\section{Prevalence}

\begin{tabular}{|l|l|l|}
\hline Year & Least Cost Rule & Systemic Failure Criteria \\
\hline 2014 & $45 \%$ & $26 \%$ \\
\hline 2015 & $42 \%$ & $23 \%$ \\
\hline 2016 & $48 \%$ & $26 \%$ \\
\hline 2017 & $47 \%$ & $28 \%$ \\
\hline 2018 & $51 \%$ & $32 \%$ \\
\hline 2019 & $65 \%$ & $49 \%$ \\
\hline 2020 & $73 \%$ & $40 \%$ \\
\hline
\end{tabular}

${ }^{24}$ Suppose we define the sample set in survey iteration $t$ as $s_{(t)}$. The intersection of $s_{(t)}$ and $s_{(t-1)}$ defines the sample common to survey iterations $\mathrm{t}$ and $\mathrm{t}-1$, and is denoted $\mathrm{s}^{*}(\mathrm{t})\left(\mathrm{s}^{*}(\mathrm{t}) \subset \mathrm{s}(\mathrm{t}), \mathrm{s}^{*}{ }_{(\mathrm{t})} \subset \mathrm{s}(\mathrm{t}-1)\right) . X_{t}^{s}$ then defines the average of data item y in survey iteration $\mathrm{t}$ based on sample $\mathrm{s}$. The full survey movement can be specified as $\Delta X_{t}=X_{t}^{s(t)}-X_{t-1}^{s(t-1)}$. The common sample survey movement can be specified as $\Delta^{c} X_{t}=X_{t}^{s *}(t)-X_{t-1}^{s *}(t)$. The absolute residual is treated as the sample rotation effect (RE) i.e. $R E_{t}=\mid \Delta X_{t}-$ $\Delta^{c} X_{t} \mid$. 
Change in prevalence and sample rotation effect

\begin{tabular}{|l|l|l|l|l|l|l|}
\hline Year & \multicolumn{2}{l|}{ Least Cost Rule } & \multicolumn{3}{l|}{ Systemic Failure Criteria } \\
\hline & $\begin{array}{l}\text { Common } \\
\text { sample }\end{array}$ & $\begin{array}{l}\text { Full } \\
\text { sample }\end{array}$ & $\begin{array}{l}\text { Rotation } \\
\text { effect }\end{array}$ & $\begin{array}{l}\text { Common } \\
\text { sample }\end{array}$ & $\begin{array}{l}\text { Full } \\
\text { sample }\end{array}$ & $\begin{array}{l}\text { Rotation } \\
\text { effect }\end{array}$ \\
\hline 2019 & $9 \%$ & $14 \%$ & $5 \%$ & $6 \%$ & $17 \%$ & $11 \%$ \\
\hline
\end{tabular}

\section{Testing for a linear trend in time series}

\begin{tabular}{|l|l|l|l|}
\hline Model & Term & Least Cost Rule & Systemic Failure Criteria \\
\hline A & Intercept & $0.29^{* *}$ & 0.14 \\
\hline A & Time & $0.05^{* *}$ & $0.04^{*}$ \\
\hline B & Intercept & $-0.48^{* *}$ & $0.55^{* * *}$ \\
\hline B & Time & $0.19^{* *}$ & $-0.10^{* *}$ \\
\hline C & Intercept & $-0.59^{* *}$ & $0.40^{* *}$ \\
\hline C & Time & $0.29^{* * *}$ & $-0.10^{* * *}$ \\
\hline
\end{tabular}

